\title{
Biological Control Perspective of Synema decoratum (Araenae: Thomisidae) against Spodoptera litura (Lepidoptera: Noctuidae)
}

\author{
Jagrati Upadhyay $^{1}$ *, S. B. Das ${ }^{1}$ and S. Chakrabarti ${ }^{2}$ \\ ${ }^{1}$ Department of Entomology, College of Agriculture, J.N.Agricultural University, \\ Jabalpur 482004 (M.P.), India \\ ${ }^{2}$ Forest Ecology \& Rehabilitation Division, Tropical Forest Research Institute, \\ Jabalpur 482021, (M.P.), India \\ *Corresponding author
}

\section{A B S T R A C T}

\section{Keywords}

Synema decoratum, Spodoptera litura, predatory potential prey

Article Info

Accepted:

14 May 2020

Available Online:

10 June 2020
The research was conducted in the Biocontrol Research and Production Centre of Jawaharlal Nehru Krishi Vishwavidyalaya Jabalpur (M.P.) to work out the predatory potential of spider Synema decoratum (Araenae: Thomisidae) against Spodoptera litura (Lepidoptera: Noctuidae). The experiment was carried in Completely Randomized Design (CRD) with ten replications. The studies revealed that the predatory potential of spiders differed from 30 to $100 \%$ i.e. the feeding rate of the spider at different prey density ranged from 1 to 3.05 tobacco caterpillars/day. Further, the logistic analysis showed that $S$. decoratum fall under III type of the functional response, according to its species and guild functions.

\section{Introduction}

Nowadays, a lot of research on the utilization of natural agents to manage insect pests is going on. These biological agents facilitate to trim down the use of chemicals to eliminate pests which thus helps in the enhancement of people's immunity and agroecosystem sustainably (Symondson et al., 2002 and Rendon, 2016). It is no exaggeration to say that spiders are important bioagent being an effective polyphagous predator both as juveniles and adults (Chakrabarti, 2013). Spiders are strictly carnivorous and can capture 5000-6000 individuals of prey during the whole of their lifetime (Pekar, 2012).

Spiders are the foremost predators in several field crops, up to 68 individuals per five square meters have been found in pigeonpea (Upadhyay et al., 2018a). There is a wide range of systems by which spiders obliterate pests (Maupin et al., 2001 and Rendon et al., 2016). 
The most important tool is a direct attack; some are dislodging them from vegetation and trapped in their web construction. It is well-known that greater biodiversity of spiders is more effective in the management of insect pests than single species of spider (Pekar, 2012).

This is for the reason that the chasing propensity of various species of spider is unusual, which in turn helps in the repression of several types of insect pests (Rendon, 2016 and Synder, 2019). Hunting by a spider is thickness - reliant that too is influenced by three attributes of predation viz., foraging behaviour, feeding and densities.

In functional response, the pace of ingestion of prey possesses increments or decreases in light of an expanded or diminished availability of prey (Pekar, 2012 and Upadhyay et al., 2018b). In differential consequence, spiders shifts from places of falling prey bulk to one that are contributing higher frequencies.

When the prey population increases, they reproduce to expand their figure with the goal that they can devour several preys (Rendon, 2016). The aspiration of the current study is proficient utilization of the spider as a biological control agent in an agroecosystem.

\section{Materials and Methods}

For conducting the studies on the functional response of wandering spiders on S. litura, the experimental details were as follows:

At BRPC, Department of Entomology, CoA, JNKVV, Jabalpur (M.P.). In the season of Kharif 2016-18. Design - CRD with 10 replication and prey: $S$. litura. Treatment details were as follows- $\mathrm{T}_{1}: 1$ larva, $\mathrm{T}_{2}: 2$ larvae, $\mathrm{T}_{3}: 3$ larvae, $\mathrm{T}_{4}: 4$ larvae, $\mathrm{T}_{5}: 5$ larvae, $\mathrm{T}_{6}: 6$ larvae, $\mathrm{T}_{7}: 7$ larvae, $\mathrm{T}_{8}: 8$ larvae, $\mathrm{T}_{9}: 9$ larvae, $\mathrm{T}_{10}: 10$ larvae. Spider species Synema decoratum were included in the study. The adult spiders were collected from the untreated crop field during the month of September- October.

The techniques adopted were locating find and hand collection and insect net sweeping (30 $\mathrm{cm}$ diameter and $60 \mathrm{~cm}$ deep), respectively. From the collected spiders, female spiders of about identical size and weight were sorted out species wise and were maintained in cages for the in vitro study.

S. litura (Fabricius) (Lepidoptera: Noctuidae) is one of the economically key and polyphagous pest on the field (Basera and Srivastava, 2010). These were multiplied and maintained under the caged condition on the potted plants of soybean (variety JS 335) as per the methodology proposed by Ramaiah and Maheswari (2018).

The pots were filled with vermicompost, soil and sand in the ratio of 2:1:1 and irrigated once in every two days. Initially, the egg mass of $S$. litura was collected from the field and were released on the soybean plants which were kept inside the screen house. The $S$. litura first instar larvae obtained from the insect culture in the second generation were used for the experiment.

The methodology proposed by Sivasubramanian et al., (2009) was followed for conducting functional response of wandering spiders against $S$. litura larvae. Initially, 100 females of a test spider were starved for $24 \mathrm{hr}$.

Two weeks old soybean twigs of about $10 \mathrm{~cm}$, were taken and the incise ends of the twigs were wrapped with moist cotton were kept in petriplates and varying population of first instar S. litura larvae were transferred on the twigs. Each petriplate was further placed in a 
plastic container (height $20 \mathrm{~cm} \mathrm{x}$ diameter 15 $\mathrm{cm})$. Thereafter, the starved spiders were introduced individually in each plastic jar which was randomly assigned to the different $S$. litura density treatments. The open mouth of the jars was covered with the muslin cloth and kept under ambient conditions $\left(25^{\circ} \pm 2^{\circ} \mathrm{C}\right.$ and $80 \pm 10 \% \mathrm{RH})$. Simultaneously, a control set of all the treatments were also designed which contained a varying population of first instar S. litura larvae, but without a spider, to work out the natural larval mortality. After 24 $\mathrm{hr}$ of the release of the spiders, the number of live larvae left in each jar was recorded and the predation percentage was computed.

\section{Statistical analysis}

Examination of different factors was established out to know the level of variation amongst all the treatments (Gomez and Gomez 1984). DMRT was computed as per the methodology proposed by Duncan (1955) for comparing the treatment means of predation percentage by spiders.

Correlation and regression of the spider predation with the prey densities were calculated by utilizing the equation as suggested by Snedecor and Cochran (1967). The functional response is a mathematical framework to depict and estimate the feeding interaction among a consumer and prey. (Holling, 1966).

\section{Types of functional response}

"Type I Prey mortality due to predation is constant.

Type II Prey mortality declines with prey density.

Type III Mortality first increases with increasing prey density and then declines." (Rui et al., 2004 and Shivakumar, 2006).

\section{Results and Discussion}

The feeding rate of the spider at different prey density ranged from $1\left(\mathrm{~T}_{1}\right)$ to 3.05 tobacco caterpillars/day $\left(\mathrm{T}_{9}\right)$ but were seen as not remarkable. The results in Table 1 showed to facilitate maximum predation $(100 \%)$ was recorded in $T_{1}$ and $T_{2}$ was significantly superior to all other treatments.

This was followed by $\mathrm{T}_{3}(98.33 \%), \mathrm{T}_{4}$

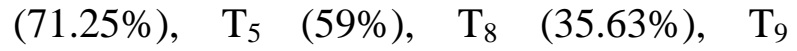
$(33.33 \%)$ while lowest predation was recorded in $\mathrm{T}_{10}(30 \%)$ and they differed significantly from each other. However, $\mathrm{T}_{6}$ (56.66\%) and $\mathrm{T}_{7}(48.56 \%)$ both were at par with each other.

It was observed that regardless of the prey population mass, the ingestion pace of $S$. decoratum be $2.63 \pm 0.01$ tobacco caterpillars per day and the percentage predation was inversely proportional to the prey density.

\section{Correlation and regression studies}

Correlation examination exposed that the prey population (tobacco caterpillars) indicated a decisive negative impact $(\mathrm{r}=-0.92)$ on $S$. decoratum predation.

The linear regression equations computed were:

$\hat{\mathrm{Y}}=111.90-9.10 \mathrm{x}\left(\mathrm{R}^{2}=0.92\right)$

The above equations express that with every unit increment in prey population, there was a decline of $9.10 \%$ predation (Fig. 1) and the coefficient of predation $\left(\mathrm{R}^{2}\right)$ was seen as $92 \%$.

The polynomial quadratic (second-order) equations processed were:

$\hat{Y}=124.00-15.15 x+0.54 x^{2}\left(R^{2}=0.94\right)$ 
The above equations demonstrate a superior fit than the straight regression, as the coefficient of predation was $94 \%$ (Fig. 1). The polynomial cubic (third-order) equations calculated were:

$\hat{Y}=104.50+2.07 x-3.18 x^{2}+0.22 x^{3}\left(R^{2}=0.96\right)$

The above conditions express as best fit than the straight and quadratic, as the coefficient of predation $\left(\mathrm{R}^{2}\right)$ was $96 \%$ (Fig. 1). A perusal of information in Table 2 on relapse investigation uncovered (logistic regression) that both the straight coefficient $\left(\mathrm{P}_{1}\right)$ and cubic coefficient $\left(\mathrm{P}_{3}\right)$ were positive, while it displayed negative quadratic coefficient $\left(\mathrm{P}_{2}\right)$, which demonstrated a sort of type III functional response.

The linear coefficient $\left(\mathrm{P}_{1}\right)$ and cubic coefficient $\left(\mathrm{P}_{3}\right)$ in the polynomial logistic regression were negative mutually with a positive quadratic parameter $\left(\mathrm{P}_{2}\right)$ which demonstrated a type II functional response. However, if the positive linear coefficient $\left(\mathrm{P}_{1}\right)$ and cubic coefficient $\left(\mathrm{P}_{3}\right)$ together with negative quadratic parameter $\left(\mathrm{P}_{2}\right)$ confirmed a type III functional response.

S. litura larval population significantly affected the extent of predation of $S$. decoratum. The predation was minimum $(30 \%)$ and maximum $(100 \%)$ at highest and lowest prey density of 10 and 1 larvae/twig, respectively and the average feeding rate of a single spider was $2.63 \pm 0.01$ larvae/day. Comparative discoveries have been documented by Sivasubramanian et al., (2009), as they also reported that the feeding rate of the spider Clubiona drassodes ranged from 0.34 to $3 \mathrm{~S}$. litura larvae/day. For a predator to be effective in the field, the feeding rate has to increase with the expansion in the prey population. A combination of the functional responses along with numerical response gives an idea of the potential of the biocontrol agent (Shivakumar and Kumar, 2010). Studies on predator ( $S$. decoratum) - prey (S. litura) association showed a type III functional response, which is in congruence with the findings of Altwegg et al., (2006), as they also reported type III functional response but in insect predators (ladybird beetle).

Spiders generally show type II response, though type III functional response is also found in the spiders, however, it is extremely uncommon. But, these kinds of functional responses of the spiders are considered to be a significant part for balancing the insect pest population and subsequently essential for biological control and it is accomplished by the capacity of the predator to gain from the past encounters (Shivakumar and Kumar, 2010).

The existing findings revealed that the spider $S$. decoratum was the efficient predator of $S$. litura larvae, as is exhibited by the extent of predation both at low and high prey population density (Nyffeler 1999; Framenau et al., 2000; Sivasubramanian et al., 2009 and Tahir et al., 2011). The present findings indicate that the $S$. decoratum which exhibited type III functional response has high predatory potential and can be efficiently used as successful biocontrol agents in varied agroecosystem.

The predator-prey interaction can be stabilized by type III responses due to consumers that increase their foraging efficiency through the creation of a search image, or by generalist predators that switch to alternative prey at low prey densities as suggested by Dunn and Hovel (2020)." The significance of present research can be stated as Synema decoratum was the efficient predator of foliage feeder (S. litura larvae), as is exhibited by the extent of predation. The spider exhibited type III functional response. 
Table.1 Impact of prey density S. litura on prey consumption by the spider, S. decoratum (Thomisidae) under laboratory conditions

\begin{tabular}{|c|c|c|c|c|c|c|}
\hline \multirow[t]{3}{*}{ Treatments } & \multicolumn{6}{|c|}{ Mean predation of S.litura larvae bv a single spider. $S$. decoratum } \\
\hline & \multicolumn{2}{|c|}{ 2016-17 } & \multicolumn{2}{|c|}{$2017-18$} & \multicolumn{2}{|c|}{ Pooled } \\
\hline & Nos./ dav* & Percentage \# & Nos./ dav* & Percentage \# & Nos./ dav* & Percentage \# \\
\hline $\mathbf{T}_{1}$ & $1.00(5.74) \mathrm{c}$ & $100.00(90.00) \mathrm{a}$ & $1.00(5.74) \mathrm{c}$ & $100.00(90.00) \mathrm{a}$ & $1.00(5.74) \mathrm{d}$ & $100(90.00) \mathrm{a}$ \\
\hline $\mathbf{T}_{2}$ & $2.00(8.13) b$ & $100.00(90.00) \mathrm{a}$ & $2.00(8.13) b$ & $100.00(90.00) \mathrm{a}$ & $2.00(8.13) \mathrm{c}$ & $100(90.00) \mathrm{a}$ \\
\hline $\mathbf{T}_{3}$ & $2.90(9.80) \mathrm{a}$ & $96.66(79.47) b$ & $3.00(9.97) \mathrm{a}$ & $100.00(90.00) \mathrm{a}$ & $2.95(9.89) \mathrm{a}$ & $98.33(82.584) \mathrm{a}$ \\
\hline $\mathbf{T}_{4}$ & $2.80(9.63) \mathrm{a}$ & $70.00(56.78) \mathrm{c}$ & $2.90(9.80) \mathrm{a}$ & $72.50(58.37) \mathrm{b}$ & $2.85(9.72) \mathrm{ab}$ & $71.25(57.58) b$ \\
\hline $\mathbf{T}_{5}$ & $2.90(9.80 \mathrm{a}$ & $60.00(50.76) \mathrm{d}$ & $2.90(9.80) \mathrm{a}$ & $58.00(49.60) \mathrm{c}$ & $2.90(9.80) \mathrm{ab}$ & $59.00(50.18) \mathrm{c}$ \\
\hline $\mathbf{T}_{6}$ & $2.80(9.63) \mathrm{a}$ & $46.66(43.08) \mathrm{e}$ & $2.80(9.63) \mathrm{a}$ & $44.99(42.12) \mathrm{d}$ & $2.80(9.63) b$ & $45.83(42.61) \mathrm{d}$ \\
\hline $\mathbf{T}_{7}$ & $2.90(9.80) \mathrm{a}$ & $46.82(43.17) \mathrm{f}$ & $3.00(9.97) \mathrm{a}$ & $42.85(40.88) d$ & $2.95(9.89) \mathrm{a}$ & $44.84(42.04) \mathrm{d}$ \\
\hline $\mathbf{T}_{8}$ & $2.90(9.80) \mathrm{a}$ & $36.25(37.01) \mathrm{fg}$ & $2.80(9.63) \mathrm{a}$ & $35.00(36.27) \mathrm{e}$ & $2.85(9.72) a b$ & $35.63(36.65)$ e \\
\hline $\mathbf{T}_{9}$ & $3.10(9.97) \mathrm{a}$ & $33.33(35.26) \mathrm{gh}$ & $3.00(9.97) \mathrm{a}$ & $33.33(35.26)$ ef & $3.05(10.06) \mathrm{a}$ & $33.33(35.26)$ ef \\
\hline $\mathbf{T}_{10}$ & $3.00(9.97) \mathrm{a}$ & $30.00(33.21) \mathrm{h}$ & $3.00(9.97) \mathrm{a}$ & $30.00(33.21) \mathrm{f}$ & $3.00(9.97) \mathrm{a}$ & $30.00(33.21) \mathrm{f}$ \\
\hline SEm \pm & 0.16 & 1.38 & 0.13 & 0.82 & 0.11 & 0.98 \\
\hline CD at $5 \%$ & NS & 3.99 & NS & 2.32 & NS & 2.77 \\
\hline
\end{tabular}

Temperature $25 \pm 2{ }^{\circ} \mathrm{C}$ and $\mathrm{RH} 80 \pm 10 \%$

$*=$ Figures in brackets are square root changed values

\# = Figures in brackets are arcsin changed values

Means in a column followed by a similar letter do not differ significantly (DMRT $<0.05)$

Nos. $=$ Numbers, NS $=$ Non-Significant

Table.2 Logistic regression investigation of the extent of prey, S. litura killed by spiders against the preliminary number of tobacco caterpillars presented

\begin{tabular}{|c|c|c|c|c|c|c|c|c|c|c|c|c|c|}
\hline \multirow[t]{2}{*}{ Spider species } & \multicolumn{5}{|c|}{ 2016-17 } & \multicolumn{4}{|c|}{$2017-18$} & \multicolumn{4}{|c|}{ Pooled } \\
\hline & Coeff & EST & SD & $\mathrm{Chi}^{2}$ & $\operatorname{Pr}\left(>\left|\mathrm{Chi}^{2}\right|\right)$ & EST & SD & Chi $^{2}$ & $\operatorname{Pr}\left(>\left|\mathrm{Chi}^{2}\right|\right)$ & EST & SD & $\mathrm{Chi}^{2}$ & $\operatorname{Pr}\left(>\left|\mathrm{Chi}^{2}\right|\right)$ \\
\hline \multirow[t]{4}{*}{ S. decoratum } & $\mathbf{P}_{0}$ & 0.02 & 0.49 & 0.00 & 0.98 & 2.00 & 0.61 & 1.05 & 0.00 & 0.66 & 0.75 & 0.77 & 0.37 \\
\hline & $\mathbf{P}_{1}$ & 0.02 & 0.78 & 0.00 & 0.98 & 0.34 & 0.81 & 0.18 & 0.66 & 0.21 & 0.59 & 0.13 & 0.71 \\
\hline & $\mathbf{P}_{2}$ & -0.23 & 1.80 & 0.02 & 0.90 & -0.54 & 1.86 & 0.08 & 0.76 & -0.04 & 0.11 & 0.11 & 0.73 \\
\hline & $\mathbf{P}_{3}$ & 0.22 & 1.07 & 0.04 & 0.84 & 0.21 & 1.11 & 0.03 & 0.84 & 0.02 & 0.07 & 0.10 & 0.75 \\
\hline
\end{tabular}

Coeff $=$ Coefficient, $\mathrm{EST}=$ Estimate, $\mathrm{SD}=$ Standard deviation, Chi $^{2}=$ Chi-square, $\mathrm{Pr}=$ Probability, $\mathrm{P}_{\mathrm{O}}=$ Constant, $\mathrm{P}_{1}=$ Linear, $\mathrm{P}_{2}=\mathrm{Quadratic}, \mathrm{P}_{3}=$ Cubic 


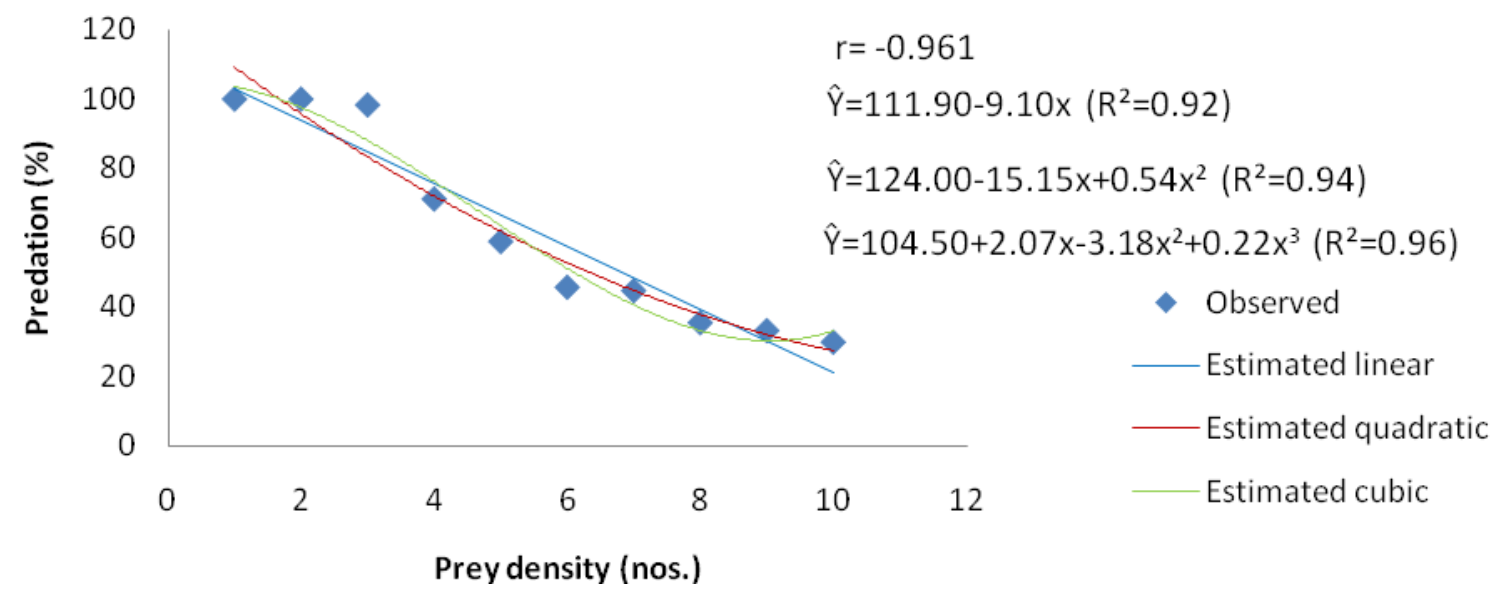

Fig.1 Regression of prey $S$. litura larval population density on predation

by the spider, $S$. decoratum

Thus, from the above treatise, it can be concluded that the spiders are important bioagent and due to their predatory behaviour they contribute significantly to the management of insect pests in various agroecosystems. Over a while, once the importance of the spiders as predators is accepted, they will become a major part of the Integrated Pest Management programme. Consequently, the use of chemicals will be reduced drastically, improving the economy and health of the country.

\section{Acknowledgements}

Department of Entomology, JNKVV, Jabalpur for providing necessary laboratory facilities.

\section{References}

Altwegg, R., Margaret, E., Caspersen, S. Bradley, R.A., 2006. Functional response and prey defence level in an experimental predator-prey system. Evolution. Ecol. Res. 8(1): 115-128.

Basera, A., Srivastava, R.P., 2010. Effect of sub lethal doses of some synthetic pyrethroids in combination with plant oils on Spodoptera litura Fab. Pest Mgt. in Horti. Ecosys. 16(2), 184-187.
Chakrabarti, S., 2013. Spiders of Western Himalaya: A pictorial field guide. Division Of Forest Protection, Himalayan Forest Research Institute, Himachal Pradesh. U.K. Publ. pp 3-4.

Duncan, D.B., 1955. Multiple range and multiple f tests. Biometrics 11(3): 1-42.

Dunn, R.P., Hovel K.A., 2020. Predator type influences the frequency of functional responses to prey in marine habitats. Biol. Lett. 16: 20190758. http://dx.doi.org/10.1098/rsbl.2019.075 8.

Framenau, V.W., Finley, L.A., Allan, K., Love, M., Shirley, D., Elgar, M.A., 2000. Multiple Feeding In Wolf Spiders: The effect of starvation on handling time, ingestion rate and inter catch intervals in Lycosa lapidosa (Araneae: Lycosidae). Australian J. of Zool 48(1): 59-65.

Gomez, K.A., Gomez, A.A., 1984. Statistical procedures for agricultural research. Publ. John Wiley and Sons. Inc. NY. pp 361-388.

Holling, C.S., 1966. The functional response of invertebrate predators to prey density. Mem. Entom. Soc. Can., 48: 186.

Maupin, J.L., Riechert, S.E., 2001. Superfluous killing in spiders: A 
consequence of adaptation to foodlimited environments? Behavi. Ecol., 12(5): 569-576.

Nyffeler, M., 1999. Prey selection of spiders in the field. The J. of Arachnol. 27(1):317-324.

Pekar, S., 2012. Spiders (Araneae) in the pesticide world: An ecotoxicological review. Pest management science. 68. 1438-46. 10.1002/ps.3397.

Ramaiah, M., Maheswari, U., 2018. Biology studies of tobacco caterpillar, Spodoptera litura Fabricius. J. of Entomol. and Zool. Stud. 6(5): 22842289.

Rendon, D., 2016. The role of wolf spider (Araneae: Lycosidae) on the biological control of the bollworm Helicoverpa spp. (Lepidoptera: Noctuidae) in cotton crops. Ph.D. Thesis, Macquarie University, Sydney. 256p.

Rui, X., Mark, C., Lansun, C., 2004. Persistence and global stability in a delayed predator-prey system with holling-type functional response. ANZIAM Journal. 46. 10.1017/S1446181100013729.

Shivakumar, M.S., 2006. Role of spiders as biocontrol agents in selected agroecosystems of Gujrat: An ecoenvironmental and IPM approach. Ph.D. Thesis, The M.S. University of Baroda, Vadodara. 210p.

Shivakumar, M.S., Kumar, D., 2010. Biological control potential of male and female Oxyopes shweta (Araenae: Oxyopidae) against polyphagous insect pest Spodoptera litura. J. of Ecobiotech. 2(5): 20-24.

Sivasubramanian, P., Vanitha, K., Kavitharaghavan, Z., Banuchitra, R., Samiayyan, K., 2009. Predatory potential of different species of spiders on cotton pests. Journal of Farm Sciences 22(3): 544-547.

Snedecor, G.W., Cochran, W.G., 1967. Statistical methods. Oxford and IBH Publishing Company, New Delhi. pp: 34-38.

Snyder, W.E., 2019. Give predators a complement: conserving natural enemy biodiversity to improve biocontrol. Biological Control 135: 73-82.

Symondson, W.C., Sunderland, K.D., Greenstone, M.H., 2002. Can generalist predators be effective biocontrol agents? Annual Review of Entomology 47(1): 561-594.

Tahir, H.M., Butt, A., Naheed, R., Bilal, M., Alam, I., 2011. Activity density of spiders inhabiting the citrus field in Lahore, Pakistan. Pak. J. of Zool. 43(4): 683-688.

Upadhyay, J., Das, S.B., Chakrabarti, S., 2018a. Diversity of spiders on post rainy season crops in Jabalpur, Madhya Pradesh. J. of Entomol. \& Zool. Stud. 6(3), 1645-1650.

Upadhyay, J., Das, S.B., Chakrabarti, S., 2018b. Predatory potential of spider, Synema decoratum (Araneae: Thomisidae) on aphid, Aphis craccivora (Homoptera: Aphididae). Int. J. of Fauna \& Bio. Stud. 5(5), 03-07.

\section{How to cite this article:}

Jagrati Upadhyay, S. B. Das and Chakrabarti. S. 2020. Biological Control Perspective of Synema decoratum (Araenae: Thomisidae) against Spodoptera litura (Lepidoptera: Noctuidae). Int.J.Curr.Microbiol.App.Sci. 9(06): 221-227. doi: https://doi.org/10.20546/ijcmas.2020.906.028 